\title{
O TOQUE TERAPÊUTICO E A EDUCAÇÃO AMBIENTAL: UM ENCONTRO RIZOMÁTICO
}

\author{
Aline Cristina Calçada de Oliveira' ${ }^{1}$, Alfredo Guillermo Martin Gentini ${ }^{2}$, Marlene Teda Pelzer ${ }^{3}$ \\ ${ }^{1}$ Enfermeira. Doutoranda em Educação Ambiental, Professora Assistente da Escola de Enfermagem da Universidade \\ Federal do Rio Grande-FURG. arilline82@yahoo.com.br \\ ${ }^{2}$ Professor Adjunto do Curso de Psicologia e Programa de Pós- Graduação em Educação Ambiental da Universidade \\ Federal do Rio Grande-FURG. \\ ${ }^{3}$ Enfermeira. Professora Associada da Escola de Enfermagem e Programa de Pós- Graduação em Enfermagem da \\ Universidade Federal do Rio Grande-FURG.
}

http://dx.doi.org/10.5902/223613086956

\section{RESUMO}

Trata-se de uma tese de doutorado em andamento cujo tema central é minimizar a iatrogenia hospitalar a partir do Toque Terapêutico. Busca redescobrir a relação entre a enfermagem e as pessoas hospitalizadas. Formulam-se três hipóteses: a construção de um espaço ecosófico é capaz de superar a iatrogenia; o hospital enquanto ambiente pedagógico propicia a formação de um novo olhar e o hospital enquanto espaço clínico deve ir além da patologia, valorizando o ser humano de forma integral. Através da cartografia analisa tais hipóteses e propõe intervenções institucionais embasadas em experimentações socioambientais, incluindo o ambiente acadêmico, o espaço clínico hospitalar bem como local afastado do perímetro urbano. O campo de intervenção desta pesquisa é composto de diversos lugares, os quais contemplam o próprio campo empírico, onde os sujeitos constroem juntos seus itinerários. Algumas experimentações envolvem um grupo de doutorandos constituído por três pesquisadores do Programa de PósGraduação em Educação Ambiental- PPGEA da Universidade Federal do Rio Grande- Furg, denominado de comunidade pesquisadora. A última contempla três áreas do conhecimento articuladas no propósito da Educação Ambiental- quais sejam: a enfermagem, a arte/educação e a sociologia. Outras buscam uma experimentação direta com pessoas hospitalizadas numa unidade de clínica médica. Em conjunto, utilizam das artes cênicas e visuais para provocar processos capazes de impulsionar um devir criativo, quer no hospital, quer na academia ou mesmo em ambiente junto a mata atlântica. Esses espaços se constituem cartograficamente de acordo com um conjunto de possibilidades que formam fluxos de acontecimentos atuais que são atravessados pelas vicissitudes dos envolvidos. As experimentações socioambientais que tem se proposto a presente tese tem demonstrado outras possibilidades de cuidado em saúde. A Esquizoanálise permite a criação de mecanismos protetores em nossas rotinas de trabalho. O Toque Terapêutico é um dos caminhos que podem ser trilhados nesse sentido. A prática do mesmo tem levado a uma ideia de pertencimento ao entorno capaz de conduzir a uma nova relação com a vida, elo indispensável defendido por todas as correntes de Educação Ambiental.

Palavras-chave: Educação Ambiental, Toque Terapêutico, Cuidado, latrogenia.

\section{ABSTRACT}

THERAPEUTIC TOUCH AND ENVIRONMENTAL EDUCATION: A RHIZOMATIC ENCOUNTER

It deals with an ongoing doctoral thesis whose central theme is to minimize hospital iatrogenesis by means of Therapeutic Touch. It aims to redefine the relationship between nursing and hospitalized people. Three hypotheses have been formulated: the construction of an ecosophical space capable of overcoming iatrogenesis; the hospital as a pedagogical environment provides the 
conception of a new view and the hospital as a clinical space must go beyond pathology, valuing each human being as a whole. Through cartography, it analyzes such hypotheses and proposes institutional interventions based on social-environmental experimentations, including the academic environment, the hospital clinical space as well as a place away from any urbanized area. The field of intervention of this research is formed by various places, which contemplate the empirical field itself, where the subjects build their itineraries together. Some experimentations involve a group of doctoral students composed by three PPGEA (Environmental Education PostGraduate Program) researchers of FURG - Universidade Federal do Rio Grande, which is called researching community. The latter contemplates three knowledge areas articulated with the purpose of EE - Environmental Education, which are: nursing, art/education and sociology. Others seek direct experimentation with people who are hospitalized in a medical clinic. As a group, they utilize visual and scenic art to start up processes capable of bringing up a creative becoming, either in the hospital, in the academic environment, or even in a place close to the Atlantic Forest. Such spaces are cartographically constituted according to a group of possibilities that form current event flows which are crossed by the vicissitudes of the ones involved. The social-environmental experimentations proposed to this thesis have demonstrated other possibilities regarding health care. Schizoanalysis permits the creation of protective mechanisms in our work routines. Therapeutic Touch is one of the ways that can be taken in that sense. Its practicing has led to an idea of belonging in the surroundings, which is capable of leading to a new relationship with life, undisputed link supported by all Environmental Education currents.

Key-words: Environmental Education, Therapeutic Touch, Care, latrogenesis.

\section{INTRODUÇÃO}

O presente artigo é fruto de uma tese de doutorado em andamento, cujo tema central é minimizar a iatrogenia ${ }^{1}$ hospitalar a partir do Toque Terapêutico (TT) e com isso redescobrir a relação entre a enfermagem e as pessoas hospitalizadas. Para tanto, utiliza os preceitos filosóficos da Esquizoanálise ${ }^{2}$, propostos pelos autores franceses Gilles Deleuze e Felix Guattari. Formularamse três hipóteses para responder o tema central:

1- A construção de um espaço ecosófico é capaz de superar a iatrogenia;

2- O hospital enquanto ambiente pedagógico propicia a formação de um novo olhar;

3- O hospital enquanto espaço clínico deve ir além da patologia, valorizando o ser humano de forma integral;

O problema que move a presente tese seguiu as quatro pistas do funcionamento da atenção do cartógrafo durante o trabalho de campo: o rastreio, o toque, o pouso e o reconhecimento atento. Para cada um desses momentos, os quais podem ser considerados rizomáticos, houve a construção de estratégias para diminuir a iatrogenia. Essas estratégias se deram através de hipóteses, as quais não se satisfizeram em responder o porquê simplesmente e para tanto se propuseram, através de análise e intervenção institucional ${ }^{3}$, a pensar no como, a partir de uma verdadeira caminhada investigativa.

A análise e intervenção institucional é um processo coletivo, cujo objetivo é propiciar que o grupo em questão se torne capaz de autoanalisar-se e de gerenciar suas próprias questões. 
(BAREMBLITT, 1992). Pode-se dizer que o movimento que levou a identificar a iatrogenia como tema central dessa tese foi justamente a articulação desses dois momentos, ou seja, a autoanálise e a autogestão. A auto-análise consiste em utilizar seu próprio saber para fazer o levantamento de suas reais necessidades e de seu potencial para resolvê-las. A capacidade de solução dos problemas levantados também deve ser buscada entre as potencialidades dos componentes do grupo, que vão inventar as estratégias de solução para os mesmos. (BAREMBLITT, 1992).

A intervenção institucional tem uma segunda fase, que não ocorre depois da primeira, mas se inicia e se propaga junto com ela, que é a autogestão. A última é uma estratégia adotada pelo grupo pesquisador no sentido de gerir todos os seus passos rumo à solução de seus problemas, e até mesmo todos os possíveis entraves com que se depararem no decorrer do processo. (BAREMBLITT, 1992).

latrogenia': A palavra iatrogenia ou iatrogênese deriva do grego e é composta por iatros, que significa médico, e gênese, origem. A inclusão do termo pathos (doença) daria origem à iatropatogênese, que seria doença causada pelo médico. Apesar desse significado neutro, do ponto de vista morfológico, o Dicionário Aurélio define iatrogenia como alterações patológicas decorrentes de um tratamento ou procedimento terapêutico. Assim, iatrogenia, e não iatropatogenia, tem sido o termo empregado mais comumentemente para identificar uma ação nociva ou maléfica. (OGUISSO; SCHMIDT, 2007, p.115).

Esquizoanálise²: é uma leitura do mundo de "tudo" o que acontece no mundo, como diz Guattari em seu livro sobre as Três Ecologias, sendo uma espécie de Ecosofia, uma "episteme" que compreende um saber sobre a natureza, um saber sobre a indústria, um saber sobre a sociedade e um saber acerca da mente. Mas um saber que por objetivo a vida, no seu sentido mais amplo: o incremento, o crescimento, a diversificação, a potencialização da vida. (BAREMBLITT, 2003: p. 15).

Intervenção Institucional ${ }^{3}$ : ação transformadora praticada segundo uma ética e uma política e formalizada em uma teoria aplicada segundo certas regras metodológicas e uma série de recursos técnicos. Todo esse procedimento parte de uma avaliação logística de disponibilidades e é planificado segundo uma estratégia que se decompõe em táticas. Seu objetivo central é propiciar nos coletivos intervindos a ação do instituinte, organizante e, no seu limite, a implantação de processos plenos e continuados de auto- análise e autogestão. (BAREMBLITT, 1992, p. 157).

As hipóteses formuladas nessa pesquisa estão ancoradas epistemologicamente nas variedades da atenção do cartógrafo. O funcionamento da atenção do cartógrafo baseia-se nos conceitos de atenção flutuante de S. Freud, de reconhecimento atento de $\mathrm{H}$. Bergson e nas contribuições da vertente fenomenológica das ciências cognitivas contemporâneas. (KASTRUP, 2007).

A cartografia está embasada no real, nos acontecimentos do dia-a-dia e também envolve uma boa dose de aventura. Dentro do contexto da Esquizoanálise, ela permite a formação de rizomas ${ }^{4}$, já que não é uma metodologia rígida. (DELEUZE; GUATTARI, 2010). As experimentações acontecem de forma itinerante, em diferentes ambientes, ora junto à mata atlântica, ora no espaço acadêmico e hospitalar de um Hospital Universitário do Rio Grande do Sul.

Quando se fala em cartografia, a prática da experimentação se faz necessária. De acordo com Gislei Lazzarotto (2012), para experimentar não basta entregar-se a experiência, mas construir um percurso de invenção. Numa pesquisa cartográfica as relações próprias de cada experiência possibilitam analisar as condições de emergência de um problema de pesquisa. Abandonar o 'ou', a dicotomia, o binarismo, e se deixar levar pela simples conjunção 'e' manter uma rede sempre aberta para colher a multiplicidade. (FONSECA; NASCIMENTO, MARASCHIN, 2012). 
Algumas experimentações envolvem um grupo de doutorandos constituído por três pesquisadores do Programa de Pós- Graduação em Educação Ambiental- PPGEA da Universidade Federal do Rio Grande- Furg, denominado de comunidade pesquisadora ${ }^{5}$. A última contempla três áreas do conhecimento articuladas no propósito da Educação Ambiental- EA- quais sejam: a enfermagem, a arte/educação e a sociologia. Outras buscam uma experimentação direta com pessoas hospitalizadas numa unidade de clínica médica. Em conjunto, utilizam das artes cênicas e visuais para provocar processos capazes de impulsionar um devir ${ }^{6}$ criativo.

O campo de intervenção dessa pesquisa é composto de diversos ambientes, os quais contemplam o próprio campo empírico, onde o sujeito e o objeto constroem juntos o itinerário a ser percorrido. De acordo com Lopes e Deihl (2012) a intervenção no campo de pesquisa cria uma tensão entre a atualização (reformulação da experiência através da explicação) e a problematização que produz posições subjetivas de invenção. (FONSECA; NASCIMENTO; MARASCHIN, 2012).

Esses ambientes se constituem cartograficamente de acordo com um conjunto de possibilidades que formam fluxos de acontecimentos atuais que são atravessados pelas vicissitudes dos sujeitos envolvidos, os quais visam, em âmbito geral, buscar maneiras de minimizar a iatrogenia através da Esquizoanálise e do TT. Por outro lado, também se preocupam em redescobrir a relação entre a enfermagem e os clientes hospitalizados utilizando o cuidado do TT.

Rizoma ${ }^{4}$ : termo adaptado pode Deleuze e Guattari da biologia para simbolizar o contrário de uma raiz, é um vínculo sem centro específico, que se dissemina e não tem limites internos que o compartimentalizem. Aquilo que circula nesse interior circula em "toda e qualquer direção", sem obstáculos morfologicamente materiais que o impeçam. (BAREMBLITT , 2003, p. 58).

Comunidade Pesquisadora : Aqui representada pelos doutorandos em Educação Ambiental, PPGE Furg, Aline Cristina Calçada de Oliveira, Augusto Luis Medeiros Amaral e Cláudio Tarouco de Azevedo.A comunidade pesquisadora se inspira na ideia do grupo-pesquisador como autor da pesquisa, um elemento essencial da metodologia sociopoética de Jacques Gauthier. Segundo ele, "não se trata de um grupo que pesquisa, mas de um ser coletivo, que se institui no início da pesquisa como grupo-sujeito de um devir". (GAUTHIER, 2009, p.17).

Devir $^{6}$ : são linhas de fuga que desfazem as essências e as significações em proveito de uma matéria mais intensiva onde se movimentam afetos. (FONSECA, NASCIMENTO, MARASCHIN, 2012, p.75).

O TT consiste numa técnica de imposição de mãos ${ }^{7}$, fundada na década de 70 , pela enfermeira Dolores Krieger. Sua prática se fundamenta no modelo de campo de energia humana de Dora Kunz, na teoria da relatividade de Albert Einsten, na mecânica quântica e na teoria de Marta Rogers. A base racional desses estudos foi, em grande parte, confirmada por Capra (1982), ao comparar descobertas da nova física com antigos ensinamentos sobre a metafísica do universo. (KRIEGER, 1979; KRIEGER, 1997; WALDOW, 2001; SÁ, 2008).

Esse estudo se ocupa inicialmente em discutir a dimensão ambiental do TT e seu potencial para minimizar a iatrogenia. O TT é muito mais do que um sistema de regras de conduta para ajudar a estimular a recuperação da doença; é também uma maneira de valorizar a condição humana que tem estado ausente da medicina moderna há muito tempo. Seu surgimento também se deu através de um encontro que potencializou seu desenvolvimento, entre a vidente Dora Kunz e a enfermeira Dolores Krieger. Essas pesquisadoras chamaram de TT uma interpretação contemporânea de várias práticas antigas de cura que tratam do uso inteligente das funções terapêuticas do campo de energia vital do ser humano. (KRIEGER, 1997). 
A concepção de Educação Ambiental aqui abordada através da filosofia da Esquizoanálise (DELEUZE; GUATTARI, 2010), situa-se dentro da lógica ecosófica de Felix Guattari (2011). Essa lógica preconiza outro modo de existência, numa perspectiva ético-estética que articula três registros, os quais estudam fenômenos complexos, que incluem a subjetividade humana, o meio ambiente e as relações sociais. Verifica-se aí a imanência dos registros ecológicos enunciados e buscam-se maneiras de transmutá-los em uma Educação Ambiental potencializadora de transformações saudáveis, dentre as quais se destacam: a relação do corpo e ambiente, a interligação dos espaços ambientais e uma nova maneira de cuidar em saúde.

A Esquizoanálise leva-nos à reflexão da condição de cada ser humano para buscar em seu entorno formas de vencer o instituído, as relações humanas que conduzem a uma lógica escravizada pela indústria do marketing, da moda, do consumo, que preconiza a maneira de pensar e agir de acordo com um padrão único de ser no mundo. Entende que assim como ocorre no meio natural, em que a natureza se rizomatiza para sobreviver e gerar beleza, o homem, a partir das relações entre si e com o entorno também tem esse potencial.

Com base nos preceitos filosóficos da Esquizoanálise, a prática do TT é capaz de inaugurar um novo tipo de relação humana, muito mais fluida e rizomática. Esse artigo se preocupa em trazer para o campo empírico, através de um exercício epistemológico intelectual, a reflexão sobre a prática do $\Pi$ atrelada ao cuidado em saúde e a educação ambiental. Essa prática tem o potencial de despertar nas pessoas um sentido de pertencimento ao universo, de harmonia e de felicidade. Isso se justifica tanto por seus preceitos históricos, como pelo tipo de postura adotada para o exercício da mesma.

\footnotetext{
Imposição de mãos ${ }^{7}$ : termo geral usado para designar um tipo de cura direta, efetuada através das mãos e às vezes também chamada de cura psíquica ou cura magnética. (GERBER, 2007, p. 442).
}

Assim, tanto as raízes históricas do $\Pi T$ como sua maneira de aplicação remete-nos a um outro paradigma de relação com a vida. A fundamentação teórica baseia-se na Teoria de Sistemas de Bertalanfy, na Física Quântica e na Ciência do Ser Humano Unitário de Martha Rogers. Essas teorias são capazes de trazer uma outra perspectiva de cuidado em saúde, corroborando a medicina vibracional ${ }^{8}$.

A partir de tais conhecimentos, pode-se entender o campo de energia humano ou aura ${ }^{9}$ integrado com a vida como um todo. (BRENNAN, 2006; CAPRA, 1982; GERBER, 2007). Foi somente nas décadas de 80 e 90 que a ciência ocidental começou a explorar mais o campo de energia humano, a partir do ressurgimento do holismo ${ }^{10}$ como paradigma do pensar. Pode-se comprovar que os organismos vivos são campos de energia que emitem ondas formadoras de uma aura energética que se expande além da pele e envolve todo o corpo. Essa aura energética pode ser detectada por meio de processos como a foto Kirlian ${ }^{11}$, a ressonância magnética e os aparelhos de detecção de energia galvânica e eletromagnética. (CAPRA, 1982; GERBER, 2008; SÁ, 2008). 
Esse novo paradigma percebe a vida como uma interação de campos energéticos abertos e em constante interação. A física moderna pode mostrar às outras ciências que o pensamento científico não tem que ser necessariamente reducionista e mecanicista, que as concepções holísticas e ecológicas também são cientificamente válidas. A Teoria da enfermeira americana Marta Rogers traz alguns princípios interessantes para se discutir nesse momento, dentre os quais será abordado a interação dos campos energéticos (humano e ambiental) através do $\Pi$. Essa teoria preconiza a promoção de uma interação harmoniosa entre o homem e o seu ambiente, sendo influenciada pela Teoria dos Sistemas e Teoria Eletrodinâmica da Física.

Para a aplicação do Toque Terapêutico leva-se em consideração a parte física do campo de energia humano (CEH), o qual tem uma simetria bilateral, é harmônico, morno e encontra-se de 4 a $6 \mathrm{~cm}$ da pele. De acordo com Gerber (2007, p.438), "a aura humana é um invólucro de energia que envolve e permeia o campo físico". Para senti-lo, o terapeuta deve ter conhecimentos específicos, no sentido do uso consciente das mãos, usando sua intencionalidade para tal. (KRIEGER, 1997; SÁ, 2008). O processo de aplicação do TT consiste numa repadronização/harmonização do campo energético humano seguindo basicamente quatro etapas:

Medicina Vibracional ${ }^{8}$ : filosofia de cura que busca tratar a pessoa como um todo, ou seja, o complexo mente/corpo/espírito, através do fornecimento de quantidades determinadas de energia de frequências específicas no sistema multidimensional humano. A medicina vibracional procura curar o corpo físico integrando e equilibrando os sistemas energéticos superiores que criam os padrões físico/celulares que se manifestam na forma de doenças. (GERBER, 2007, p. 443).

Aura $^{9:}$ o campo de energia humana ou aura humana é uma manifestação da energia universal intimamente ligada à vida. Pode ser entendido como um corpo lum inoso que cerca o corpo físico e o penetra, emitindo sua radiação característica própria. (BRENNAN, 2006).

Holismo ${ }^{10}$ : termo relativo a uma abordagem sinérgica que considera simultaneamente os aspectos físicos, mentais, emocionais e espirituais da saúde e das doenças. (GERBER, 2007, p. 442).

Fotografia Kirlian ${ }^{11}$ : processo eletrográfico desenvolvido originalmente na Rússia pelo engenheiro elétrico Semyon Kirlian. A fotografia Kirlian utiliza o fenômeno do efeito carona para registrar em filme fotográfico os processos bionergéticos dos sistemas vivos. (GERBER, 2008, p.442).

1- O centramento físico e psicológico. Trata-se em encontrar em nosso íntimo um ponto de referência estável;

2- $\quad$ Ativação da sensibilidade natural das mãos para avaliar o campo energético do paciente, procurando diferenças na qualidade desse fluxo;

3- Mobilização das áreas do campo energético do paciente que o agente de cura percebe como entorpecidas, congestionadas ou estagnadas e

4- $\quad$ Direcionamento consciente que o agente de cura faz do excedente de suas próprias energias físicas para ajudar o paciente a reequilibrar seu próprio campo de energia. (KRIEGER, 1979; KRIEGER, 1997).

Como se pode perceber, para aplicar o TT é necessário que se tome uma outra postura em relação a si mesmo, ao outro e a vida como um todo. Sua prática permite que se perceba de forma efetiva nossa interconexão com a natureza, unindo saberes e inaugurando um novo paradigma ${ }^{\mathbf{1 2}}$, numa nova visão da realidade, uma mudança fundamental em nossos pensamentos, percepções e valores. (CAPRA, 1982).

Por outro lado, empregar tal conhecimento no campo empírico leva a uma responsabilidade e um senso de pertencimento ao planeta capaz de inaugurar um novo conceito de Educação Ambiental. Nesse sentido, ela não é mais entendida de uma forma simplista e separada do ser 
humano, mas um verdadeiro encontro rizomático que passa pelo processo de cuidar e ser cuidado em todas as circunstâncias. Para vivenciar tais aspectos, faz-se necessário ampliarmos nossa percepção de mundo, entendendo as relações humanas como potenciais articuladores de vida, alegria e bem-estar.

Levando esses conceitos para o contexto hospitalar, pode-se dizer que o hospital não começa e nem termina nas portas que conduzem às suas dependências físicas internas. Mais do que isso, ele é composto por pessoas que recebem a dor e o sofrimento de uma forma talvez já escravizada e estereotipada. Parece ser um local destinado para a doença e não para o cuidado à saúde. Essa característica leva a uma rotina sacrificante para quem cuida e para quem é cuidado.

Tais aspectos geram relações iatrogênicas, reforçando ainda mais a doença. A iatrogenia é entendida não somente no sentido denotativo, definida como a parte da medicina que estuda a ocorrência de doenças que se originam do tratamento de outras, a patologia da terapêutica. Abrange também uma noção maléfica do ato de vários profissionais da saúde em relação à pessoa hospitalizada, não só danos materiais (uso de medicamentos, cirurgias desnecessárias, mutilações etc.), mas também psicológicos (comportamentos, atitudes e palavras). Soma-se a isso a insipiência de métodos de avaliação estatística para aferir a frequência da iatrogenia, não só no Brasil como nos países do Primeiro Mundo. A falta de parâmetros para lidar com a iatrogenia transforma-a num mito. (BOTSARIS, 2001; TAVARES, 2007).

\footnotetext{
Paradigma $^{12}$ : em linhas gerais significa modelo. 0 termo foi adotado cientificamente pelo físico Thomas Khun, em 1962, que afirma que a palavra pretende sugerir que certos exemplos da prática científica atual, tanto na teoria quanto na aplicação, estão ligados a modelos conceituais de mundo dos quais surgem certas tradições de pesquisa. (SÁ, 2008, p. 1).
}

Tanto a Esquizoanálise quanto o Toque Terapêutico permitem um processo de experimentação, o qual tem um potencial capaz de impulsionar outros modos de existência, através da reinvenção de maneiras de ser no seio do casal, da família, do contexto urbano, do trabalho etc. (GUATTARI, 2011). Uma nova maneira de cuidar em saúde implica em criarmos mecanismos que não transformem a iatrogenia num mito e invistam em relações humanas mais saudáveis, como forma de amenizá-la. Sua intenção é produzir formas de subjetivação que permitam que o humano lide de modo diferenciado com as instâncias da verdade, do saber e do poder instituídos.

A partir do momento em que as pessoas passam a se relacionarem entre si, levando em consideração instâncias mais sutis da vida, como a aura humana, sentindo que tudo que nos cerca é feito também dessa energia, elas terão mais possibilidades de buscarem caminhos mais harmoniosos, ou seja, uma nova suavidade ${ }^{13}$ de existência. Esse senso de pertencimento e responsabilidade causa grandes impactos em tendências egoísticas, em relações humanas hierarquizadas e coercitivas de ser.

Esses caminhos suaves, num contexto hospitalar, tendem a aproximar o cuidar em saúde muito mais com a vida, com o cotidiano, com o social. Dentro da perspectiva da Esquizoanálise, 
cada momento de interação com as pessoas hospitalizadas, por exemplo, pode ser uma ressignificação do que é "clinicar ${ }^{14 "}$.

A clínica torna-se inseparável da arte, pois permitimos o experimentar, o devir, uma dimensão bem diferente das "fórmulas clínicas a que estamos habituados". A imposição de mãos através do TT permite abrir fissuras, rupturas nas certezas instituídas em nós. E isso gera num primeiro momento medo, angústia, por que se precisa sair da zona de conforto de um conhecimento que se aplica de forma geral, como se todas as pessoas fossem iguais, para um conhecimento que vem com o devir, com a experiência de construção com o outro.

Por outro lado, é um movimento que vale a pena vivenciar, um espaço de clinamen ${ }^{15}$ capaz de ressignificar as relações dentro das instituições de saúde. Chegar numa pessoa hospitalizada e oferecer-lhe suas mãos como forma de tratamento, ou seja, oferecer amor, é muito mais complexo. Nesse sentido, é um resgate do ser humano com seus múltiplos devires, o devirplaneta, o devir- cuidado etc. Nesse sentido fica evidente que nos construímos desses clinamens que geram pequenos desvios nas certezas instituídas. Faz-se uma prática clínica muito mais pela dúvida, pelas incertezas,

Nova suavidade ${ }^{13}$ : relaciona-se com a organização de novas solidariedades, novas práticas micropolíticas e microssociais que se aproximem de práticas estéticas, as quais trabalhem para a humanidade e não mais para um simples reequilíbrio permanente do universo das semióticas capitalísticas. (GUATTARI, 2011, p.35).

Clinicar $^{14}$ : sua raiz etimológica vem do grego Klinikos, que tem o sentido de 'debruçar-se sobre o leito' de um indivíduo moribundo para restituir-lhe um estado perdido. (FONSECA, NASCIMENTO, MARASCHIN, 2012, p.49).

Espaço de clinamen ${ }^{15}$ : um acontecimento se faz clínico quando é capaz de produzir rupturas, catalizar fluxos e decompor-se em diversos outros, carregando a potência de ser um analisador do mundo por vir. É um espaço onde modos cansados e adoecidos de viver são colocados em processo de destruição, ao mesmo tempo em que se criam novos territórios existenciais. (FONSECA, NASCIMENTO, MARASCHIN, 2012, p.50). Também é um vocábulo derivado do grego que significa desvio, invenção e que alude à idéia "democritiana de que le realidade esta constituída por "átomos que caen em le vecio según trayectorias rectas". Cuando uno de ellos se "desvia" y entra en colisión con outro, em um mínimo de tempo pensable, se crea una nueva unidad, inexistente hasta el momento, que constituye una "invención". A esse "desvio" se le denomina Klinanen. (BAREMBLITT, 2000, s/p).

do que por modelos prontos do que é o ser humano. Fonseca e Farina $(2012$, p.49) abordam o deslocamento da palavra clínica de sua raiz etimológica grega Klinikos, que tem o sentido de 'debruçar-se sobre o leito' de um indivíduo moribundo para restituir-lhe um estado perdido. (FONSECA, NASCIMENTO, MARASCHIN, 2012).

Historicamente, antes de ser comprovada a eficácia do $T T$ em seres humanos, foi ratificada sua eficácia com plantas, pois após a impostação das mãos pelo TT aumentava a clorofila dos vegetais. Assim, a enfermeira Krieger (1997), entendeu que se o TT funcionava com plantas, 
também poderia ser eficaz com seres humanos, já que as moléculas de clorofila ${ }^{16}$ e de hemoglobina ${ }^{17}$ são semelhantes. Depois de vários estudos, finalmente se comprovou que o TT era capaz de aumentar os níveis de hemoglobina humana. Esse é um marco importantíssimo, pois nos liga a natureza de forma visceral, pois não traz a valorização da vida de forma antropocêntrica, ao contrário, abre-se de forma pluralizada para suas múltiplas formas de existência. A ciência moderna à luz do paradigma einsteiniano é capaz de validar a medicina vibracional ou energética, e com isso aproximar-se cada vez mais um cuidado que situe o ser humano de forma holística. (GERBER, 2007).

Concordo com Santos et al. (2001), que discutir a ecologia no cuidado com o corpo na enfermagem nos leva a enfocar os sujeitos envolvidos no processo (equipe de enfermagem e clientes), enquanto campos energéticos pulsáteis e altamente vulneráveis a absorver vibrações circundantes no ambiente. Lembrando que a enfermagem tem como uma de suas principais características e funções atuar para a "promoção da saúde", urge buscarmos formas complementares que venham a amenizar o ambiente hostil que nós mesmos construímos em nossos hospitais.

Como destacam Santos et al.(2001), uma ecologia para e da enfermagem assistencial precisa ser pensada pelas enfermeiras, não apenas como o ambiente onde o cliente se encontra e seus pertences (cama, mesinha-de-cabeceira, comadre, entre outros). Sentir o outro envolve um saber que ultrapassa o conhecimento clássico em enfermagem, e que implica em mergulhar com sumo cuidado no inconsciente do outro. Guattari (2011) nomina esse inconsciente de fatores subjetivos, em que se desenvolvem produções de subjetividade, com a tecnologia, a informação e a comunicação operando na subjetividade humana, não apenas no seio das memórias e da sua inteligência, mas também na sua sensibilidade, dos seus afetos, de seus fantasmas.

Assim, a temática ambiental nos faz refletir, por exemplo, acerca das práticas médicas e nossa relação com o corpo e com a vida. A capitalização e consequente superespecialização da medicina levou-nos a tendência de dissecar o corpo humano num processo que desarticula o organismo em partes, bem como as sutis relações entre a saúde física e mental em seus complexos fatores condicionantes sociais. Isso culminou com uma orientação muito mais voltada para a cura da enfermidade do que para a prevenção, chegando a "perverter a prática médica". (LEFF, 2008).

\footnotetext{
Clorofila ${ }^{16}:$ substancia corante verde das plantas, essencial para a realização da fotossíntese. Ocorre apenas na presença de luz e onde há ferro disponível na célula. (MICHAELIS, 2000, p.520).

Hemoglobina $^{17}$ : macromolécula existente nos glóbulos vermelhos do sangue responsável pelo transporte de oxigênio a todos os sistemas celulares do corpo. (GERBER, 2007, p. 442).
}

Reportando ao ambiente hospitalar, percebe-se um espaço iatrogênico, em que trabalhadores da saúde e clientes encontram-se sufocados pelo ar viciado, sem um contato com a natureza e isso se reflete na própria saúde e nas relações pessoais. Alguns estudos identificam 
como fatores iatrogênicos as infecções hospitalares, resultantes, por exemplo, da inadequação de planta física e instalações, falta de material e equipamentos, desproporção entre o número de profissionais e o número de leitos ocupados. Também as relacionadas aos medicamentos, como administração incorreta de fármacos. Pesquisa desenvolvida no período de janeiro de 2000 a fevereiro de 2009 em relação à abordagem de publicações científicas em enfermagem sobre iatrogenias conclui que os recursos humanos são os principais responsáveis por esses eventos. (TURRINI, 2000; SANTOS, CEOLIM, 2009; FARIAS et al., 2010).

As experimentações socioambientais que tem se proposto a presente tese tem demonstrado outras possibilidades de cuidado em saúde. Exemplifica tais experimentações em três momentos diferentes, vivenciados com pessoas e ambientes distintos, cujo objetivo foi aproximar o cuidado de enfermagem de uma concepção mais sistêmica ${ }^{18}$ da vida.

A comunidade pesquisadora propôs duas atividades para refletir sobre o TT e a iatrogenia. Em ambiente afastado do perímetro urbano, no Sítio Santa Isabel, em São José do Norte- RS, envolvendo apenas os três doutorandos realizou uma prática de impostação de mãos entre si em abril de 2011, buscando uma interação com a natureza, no sentido de chamar a atenção para o cuidado do outro e de si mesmo. O cuidado de si, como assevera Foucault (2010), também é uma maneira de cuidar do outro e de fazer bom uso da liberdade, já que sua prática se dá a partir das relações de poder.

Posteriormente, em maio de 2011 realizou na área acadêmica do Hospital Universitário (HU) da Furg, durante a 35a Semana Riograndina de Enfermagem, momentos de reflexão sobre ética e cuidado em saúde a partir de uma mesa redonda intitulada "Ética e cuidado de si: a percepção sensivel do ambiente" (realizada em 13.05.2011), utilizada como estratégia para sensibilizar os estudantes para a oficina "Experimentações Estéticas: Clownificando o ambiente hospitalar" (realizada em 14.05.2011). Esse evento contou com a participação de profissionais da área da saúde, bem como docentes e discentes.

Essas atividades potencializaram para que em maio de 2012 pudesse aplicar o TT em duas pessoas hospitalizadas em unidade de clínica médica. Percebeu-se a diminuição do estresse tanto de quem recebeu, como também da equipe que cuidava. Por outro lado, profissionais e alunos envolvidos num atendimento hospitalar que tem a possibilidade de agregar a arte, a música, o teatro, a dança, entendem seu fazer de uma perspectiva menos coercitiva, auxiliando para que a sobrecarga de trabalho não se transforme em iatrogenia. A Esquizoanálise permite a criação de mecanismos protetores em nossas rotinas de trabalho. Pude comprovar que o TT é um dos caminhos que podem ser trilhados nesse sentido. A prática do mesmo propicia uma nova relação com a vida, elo indispensável defendido por todas as correntes de Educação Ambiental.

Concepção Sistêmica ${ }^{18}$ : prima por uma ética ecológica profunda, especialmente na ciência, uma vez que a maior parte daquilo que os cientistas fazem não atua no sentido de promover a vida, nem de preservar a vida, mas no sentido de destruir a vida. (CAPRA, 1996, p.28). 


\section{REFERÊNCIAS}

BAREMBLITT, G. Apostila do Curso de formação em esquizodrama (esquizoanálise). Belo Horizonte: Instituto Félix Guattari, 2000.

BAREMBLITT, G. Compêndio de Análise Institucional e outras Correntes Teoria e Prática. 1ạ ed. Editora Record, 1992.

BAREMBLITT, G. Introdução à Esquizoanálise. Belo Horizonte: Biblioteca do Instituto Félix Guattari, 2003. $138 p$.

BRENNAN, B.A. Mãos de Luz: Um guia para a Cura através do Campo de Energia Humano. São Paulo: Pensamento, 2006.

BOTSARIS, A. Medicina Ecológica: Descubra como cuidar da sua saúde sem sacrificar o planeta. Rio de Janeiro: Nova Era, 2010.

BOTSARIS, A. Sem Anestesia: O Desabafo de um médico. Rio de Janeiro: Objetiva, 2001.

CAPRA, F. A Teia da Vida. São Paulo: Cultrix. 1996.

CAPRA, F. O Ponto de Mutação. São Paulo: Cultrix,1982.

DELEUZE, G; GUATTARI, F. O Anti Édipo. Rio de Janeiro: Editora 34, 2010.

FARIAS, G.M. et. al. latrogenias na Assistência de Enfermagem: Características da Produção Científica no período de 2000 a 2009. Revista Científica Internacional, Ano 3- N.ำ1, Janeiro/Fevereiro, 2010.

FONSECA, T.; NASCIMENTO, M. e MARASCHIN, C. Pesquisar na diferença: um abecedário. Porto Alegre:

Sulina, 2012.

FOUCAULT, M. Ética, Sexualidade, Política. 2ed. Rio de Janeiro: Gen, 2010.

GUATTARI, F. As Três Ecologias. 21 ed. Campinas, SP: Papirus, 2011.

GERBER, R. Medicina Vibracional: uma medicina para o futuro. 9 ed. São Paulo: Cultrix, 2007.

LEFF, E. Saber Ambiental. 6 ed. Petrópolis, RJ: Vozes, 2008.

MICHAELIS. Moderno dicionário da língua portuguesa. 1v. São Paulo: Melhoramentos, 2000.

OGUISSO, T.; SCHMIDT,M.J. História e Exercício da Enfermagem. 2 ed. Rio de Janeiro: Guanabara Koogan, 2007.

KASTRUP, V. O funcionamento da atenção no trabalho do cartógrafo. Psicologia \& Sociedade. Vol.19 no1 Porto Alegre Jan/abril, 2007.

KRIEGER, D. As Mãos: como usá-las para ajudar ou curar. São Paulo: Cultrix, 1979.

KRIEGER, D. Toque Terapêutico: novos Caminhos da Cura transpessoal. São Paulo: Cultrix, 1997.

SÁ, A.C. Toque Terapêutico: Pelo Método Krieger- Kunz. São Caetano do Sul, SP: Yendis, 2008.

SÁ, A.C. de. Toque Terapêutico como Assistência Complementar de Enfermagem. Acta Paul. Enf., São Paulo, v.11, n 2, p.73-76, 1998.

SANTOS, I.; FIGUEIREDO, N.M.A.; DUARTE, M.J.R.S.; SOBRAL, V.R.S.; MARINHO, A.M. Enfermagem

Fundamental. São Paulo: Atheneu, 2001- v.1.

SANTOS, J.C.; CEOLIM, M.F. latrogenias de enfermagem em pacientes idosos hospitalizados. Revista Esc. Enferm USP 2009; 43(4):810-7.

TAVARES, C. Reflexões acerca da latrogenia e Educação. Revista Brasileira de Educação Médica, 31(2): 180185, 2007.

TURRINI, R.N.T. Percepção das Enfermeiras sobre fatores de risco para a infecção hospitalar. Ver. Esc. Enf. USP, v. 34, n.2, p.174-84, jun.2000.

WALDOW, V.R. Cuidado Humano: o resgate necessário. 3 ed. Porto Alegre: Sagra Luzzatto, 2001. 